\title{
A Systematic Review and Meta-Analysis of Combined Antibiotic Spacer with Ilizarov Methods in the Treatment of Infected Nonunion of Tibia
}

\author{
Zhibo Deng $\mathbb{D}^{1}{ }^{1}$ Yuexi Mu, ${ }^{1}$ Xianding Sun, ${ }^{1}$ Yongqing Xu, ${ }^{2}$ Fubing Li $\mathbb{D},{ }^{2}$ \\ and Liangjun Yin (iD) ${ }^{1}$ \\ ${ }^{1}$ Department of Orthopaedic Surgery, Second Affiliated Hospital of Chongqing Medical University, Chongqing, China \\ ${ }^{2}$ Department of Orthopaedic Surgery, 920th Hospital of Joint Logistics Support Force, Kunming, Yunnan Province, China \\ Correspondence should be addressed to Fubing Li; lfbingwilson@sohu.com and Liangjun Yin; albertyin.21@163.com
}

Received 20 October 2020; Revised 28 December 2020; Accepted 4 January 2021; Published 18 January 2021

Academic Editor: Dominique Monlezun

Copyright (C) 2021 Zhibo Deng et al. This is an open access article distributed under the Creative Commons Attribution License, which permits unrestricted use, distribution, and reproduction in any medium, provided the original work is properly cited.

\begin{abstract}
Background. The objective of this systematic review was to evaluate current studies available reporting the antibiotic spacer combined with Ilizarov methods in the treatment of infected nonunion of tibia and to perform meta-analysis of bone results and infection recurrence to assess the efficacy of an antibiotic spacer combined with Ilizarov methods. Methods. The MEDLINE, Embase, Cochrane Library, CNKI, and CBM (Chinese Biological Medicine) databases were searched for articles published between January 2000 and July 2020. Assessment of study quality was performed using a modified version of the NewcastleOttawa scale. Effect size and 95\% confidence intervals were calculated for the main outcome. Heterogeneity was assessed. Fixedeffect modeling and Stata version 15.1 were used to analyze the data. Sensitivity analyses were conducted with the evidence of heterogeneity. Results. 11 studies involving 210 patients with infected nonunion of tibia were finally included in our metaanalysis. Bone results and infection recurrence were analyzed based on the single-arm meta-analysis. The average of external fixation index (EFI) was 46.88 days/cm in all studies included. The excellent rate in bone results and the rate of infection recurrence was $65 \%\left(95 \% \mathrm{CI}\right.$ : $\left.[0.22,0.97], I^{2}=0.0 \%, P=0.932\right)$ and $6.99 \%\left(95 \% \mathrm{CI}:[0.052,0.325], I^{2}=0.0 \%, P=1.000\right)$ in patients with infected nonunion of tibia treated with an antibiotic spacer combined with Ilizarov methods. Conclusions. Our meta-analysis revealed that the patients with infected nonunion of tibia treated with an antibiotic spacer combined with Ilizarov methods had a high rate of excellent bone results and a low rate of infection recurrence. Therefore, combining the antibiotic spacer with Ilizarov methods may be an applicable choice for repairing and reconstructing infected nonunion of tibia.
\end{abstract}

\section{Introduction}

Infected nonunion of tibia is a common complication after open tibial fracture caused by high-energy trauma and is a difficult problem for orthopedic doctors all over the world [1]. It needs long hospital stay and a high cost, leading to burden on both patients and society, of which the final result is often amputation [2,3]. Current recognized methods for cases with large defects are autologous bone graft with blood vessels, allograft, bone transport, and the Masquelet technique [4].

The vascular bone graft has the disadvantage of donor site damage and the risk of failure of the recipient site [5].
Because of the high cost of allograft transplantation, it will bring financial pressure to patients with large bone defects. For the Masquelet technique, also known as the induced membrane technique, although it has been used for various bone defects caused by infection, trauma, and tumors [6], a few studies have reported that the results are not satisfactory in severe complex open fractures $[7,8]$. The Ilizarov technique can compensate for the bone defects left by excision of the infected bone with bone transport and reconstruct the length and structure of the limb. For patients with large segmental tibial defects, it is more effective, safer, and of low expense $[9,10]$. Thus, the Ilizarov technique is now 
considered to be an ideal surgical treatment [11]. But the Ilizarov bone transport still has the possibility of infection recurrence [12]. Antibiotic cement can be used as a spacer for the bone loss area, forming soft tissue tunnel for bone transport and forming a self-induced membrane around the bone cement, which is conducive to bone regeneration [13].

Although the Ilizarov methods combined with the antibiotic spacer for the treatment of infected nonunion of tibia in clinical work have yielded satisfying results in most studies, in some studies, the opposite conclusion has been drawn [14]. Therefore, it is necessary to make a systematic summary on whether the antibiotic spacer combined with Ilizarov methods in the treatment of infected nonunion of tibia is worth recommending. However, no systematic research has been established. Therefore, we conducted a systematic review and meta-analysis of the relative literature to assess and quantitate the true effect and draw valuable conclusions.

\section{Materials and Methods}

2.1. Search Strategy. The MEDLINE, Embase, Cochrane Library, CNKI, and CBM (Chinese Biological Medicine) databases were searched for articles published between January 1,2000 , and July 30,2020 . The search strategy included following main search terms: "infected nonunion OR infection" AND "antibiotic cement OR PMMA OR spacer" AND "Ilizarov method OR Ilizarov technique OR bone transport" and so on. We also manually retrieved reference lists from the identified studies and relevant review studies for additional studies. Assessment of study quality was performed using a modified version of the Newcastle-Ottawa scale for included studies.

2.2. Selection Criteria. To minimize difference, studies were included if they met the following criteria:

(1) Article types: original articles of randomised controlled trial (RCT), retrospective or prospective trials, and reported more than five cases

(2) Target population: patients with infected defect or nonunion of the tibia with or nonsoft-tissue defects, age $>16$ years old and $<60$ years old

(3) Intervention: managements combined Ilizarov circular external fixator with antibiotic spacer, Ilizarov methods including bone transport, acute compression and lengthening, and compression osteosynthesis

(4) Outcomes: the data of the eligible patient was complete

The exclusion criteria were as follows:

(1) Article types were conference abstracts, letters, metaanalyses, case reports, or reviews

(2) Full text was not available and studies with ambiguous results

(3) Duplicates of previously published papers
(4) Studies that included children ( $<16$ years old) and the aged ( $>60$ years old)

In addition, if the sources of the study population overlapped in two or more articles, only the study with the larger number of participants or the most recent study was included.

2.3. Data Extraction. We extracted the following data from the included articles.

(1) Basic information: first author, publishing date, country, publishing journal, number of patients, demographic data of participants including age and gender, and mean previous surgical procedures, mean length of the bone defect, and mean length of follow-up

(2) Techniques: design type and administration approach

(3) Outcomes: bone results evaluated by the Paley method (rated as excellent, good, fair, and poor), functional results evaluated by the Paley method, complications per patient, external fixation time, and external fixation index reported in days $/ \mathrm{cm}$ (EFI), infection recurrence, and other complications (pin-track infection, axial deviation, bone grafting, loosening of wires, breakage of wires, malunion, refracture, knee stiffness, ankle stiffness, amputation, limb edema, and peroneal nerve palsy et al.)

All the relevant data meeting the inclusion criteria were extracted independently by 2 authors, and any disagreement between them was resolved by discussion with each other.

2.4. Statistical Analysis. The pooled result of incidence rate of bone results, functional results, and complications in each included studies were analyzed by using the data-processing software Stata 15.1. Differences were expressed as the effect size (ES) with 95\% confidence interval (CI) for the rate meta-analysis. Since in the most included studies, the incidence rate of the original data was not in the range of $30 \%$ to $70 \%$, it was firstly converted by the arcsine transformation method to make it conform to the normal distribution. Then, the conclusion was restored using the formula $P=(\sin (x / 2))^{2}$ to reach the final version. Statistical heterogeneity among studies was assessed using the standard chisquare test and $I^{2}$ statistic. $I^{2}>50 \%$ was considered to have significant heterogeneity and the random-effect model was used, while $I^{2}<50 \%$ was considered to have low heterogeneity and the fixed-effect model can be used. Other major data extracted in this research were statistically analyzed using weighted means based on the sample size of each study by SPSS 23.0, including number of patients, mean age, mean previous surgical procedures, mean length of follow-up, mean length of the bone defect, external fixation time, external fixation index (EFI), and complications per patient. Sensitivity analysis was performed to determine if the results showed differences. 


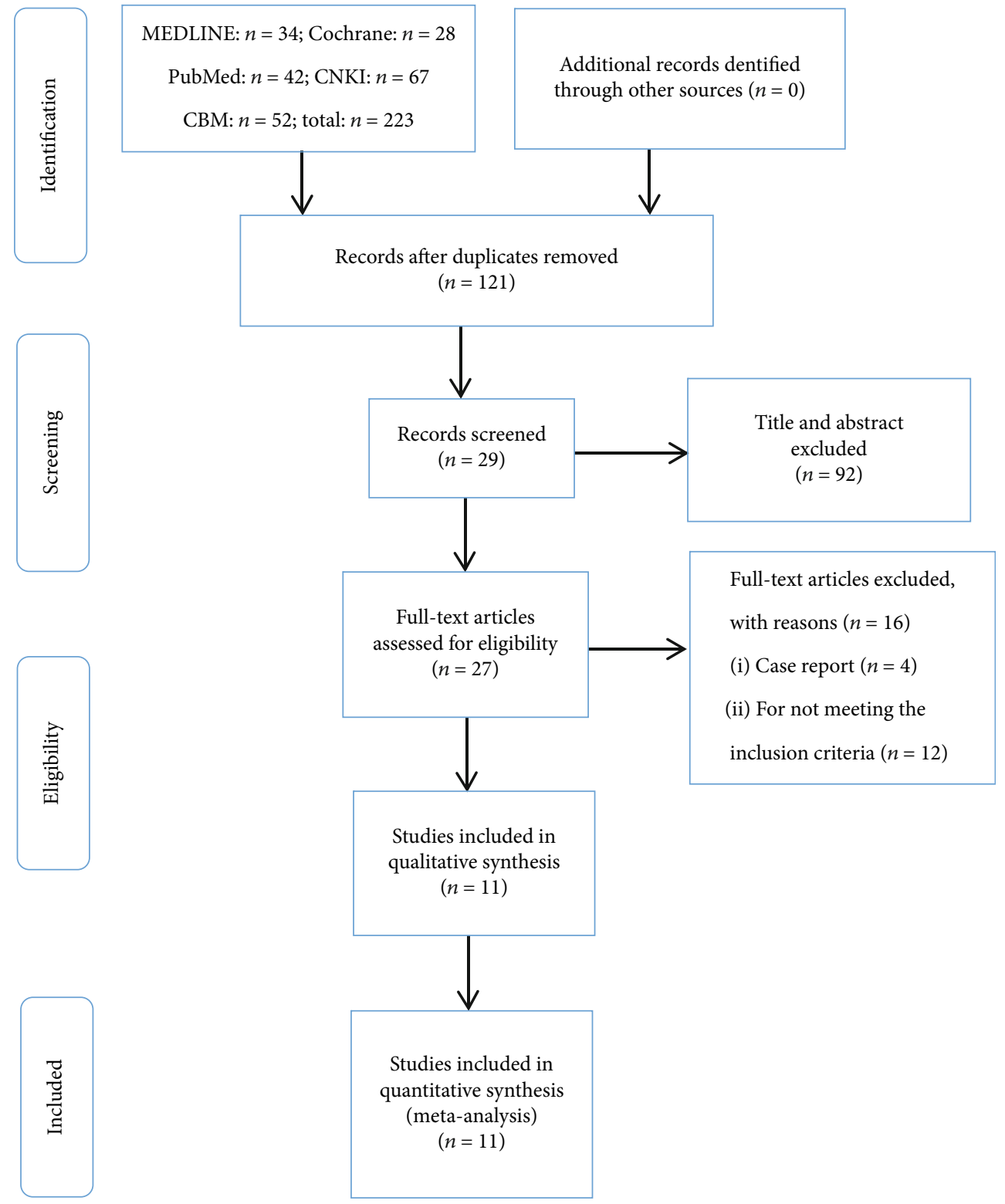

FIgURE 1: The flow chart of literature screening.

\section{Results}

3.1. Included Literature. As shown in Figure 1, initially, a total of 223 potentially relevant articles were identified from the databases, in which 121 were screened. After screening the titles and abstracts, 118 were excluded. A total of 27 fulltext articles were assessed for eligibility, while 16 were excluded for different reasons. Ultimately, 11 studies met the inclusion and exclusion criteria in our systematic review [14-24]. Of the included studies, 6 studies were retrospective case series $[15,18-20,22,23], 4$ researches were retrospective comparative studies $[14,17,21,24]$, and 1 study was a prospective case series [16]. The quality of the included studies using a modified Newcastle-Ottawa scale (score range, 0-7) ranged from 5 to 7 , with 5 positive answers taken to define a good quality study. The total scores were mainly 5 or 6, corresponding to moderate quality. Overall, the quality of the eleven included studies was moderate. The detailed assessment is shown in Table 1.

3.2. Patient Information. The studies were published between 2004 and 2019. A total of 210 patients with infected nonunion of tibia treated by combined antibiotic spacer with Ilizarov methods were included in our study. The mean age of all patients was 36.5 years. Patients had an average of 5.46 previous surgical procedures before receiving the treatment of Ilizarov methods combined with antibiotic spacer $[14,19,20]$. The mean length of the bone defect in the patients was $7.92 \mathrm{~cm}[14,16-23]$. The mean length of follow-up was 27.4 months in the patients [14-16, 18-20, 22, 23]. Table 2 summarizes the baseline characteristics of the included studies and patients. 


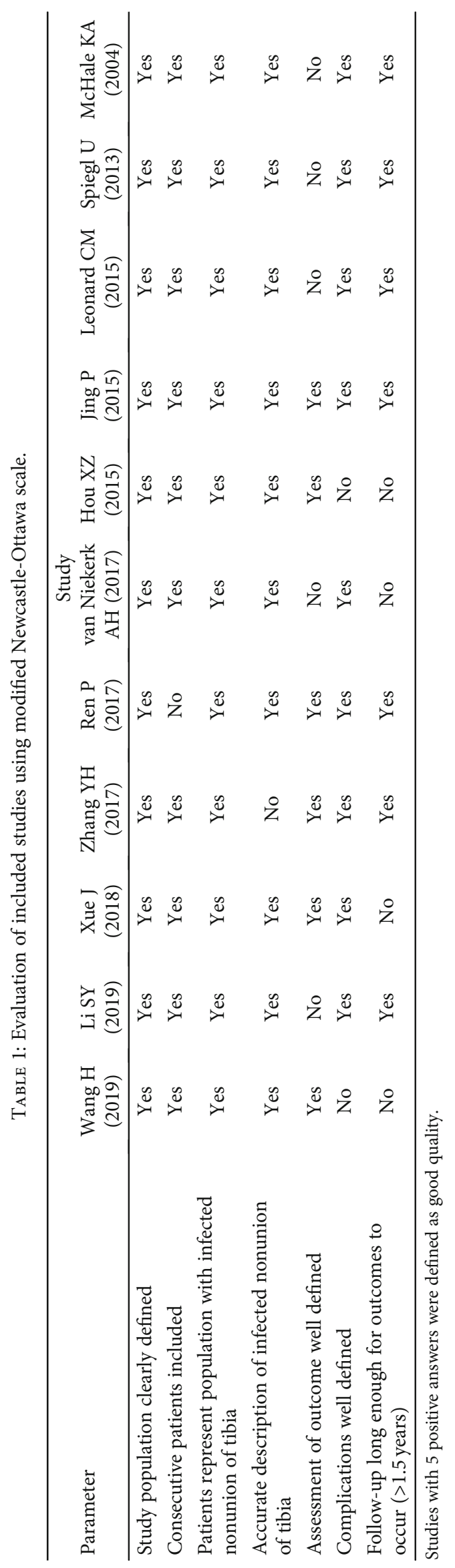


TABLE 2: Characteristics of included studies.

\begin{tabular}{|c|c|c|c|c|c|c|c|c|c|c|}
\hline $\begin{array}{l}\text { Study } \\
\text { no. }\end{array}$ & First author & Year & $\begin{array}{l}\text { Study } \\
\text { design }\end{array}$ & $\begin{array}{c}\text { Number of } \\
\text { patients }\end{array}$ & Men/women & $\begin{array}{c}\text { Age } \\
\text { (years) }\end{array}$ & $\begin{array}{c}\text { Mean } \\
\text { previous } \\
\text { operations } \\
\text { (per patient) }\end{array}$ & $\begin{array}{l}\text { Mean bone } \\
\text { defects } \\
(\mathrm{cm})\end{array}$ & $\begin{array}{l}\text { Mean time from } \\
\text { initial treatment } \\
\text { (months) }\end{array}$ & $\begin{array}{l}\text { Follow- } \\
\text { up } \\
\text { (months) }\end{array}$ \\
\hline 1 & Wang [24] & 2019 & $\mathrm{RC}$ & 31 & $18 / 13$ & 44.68 & 7.5 & - & 7.48 & - \\
\hline 2 & $\mathrm{Li}[23]$ & 2019 & RS & 18 & $11 / 7$ & 41.2 & 18 & 11.8 & 11.1 & 21.5 \\
\hline 3 & Xue [22] & 2018 & RS & 12 & $9 / 3$ & 31.5 & - & 10 & - & 14.5 \\
\hline 4 & Zhang [14] & 2017 & $\mathrm{RC}$ & 8 & - & 41.3 & 3.1 & 6.4 & 22.8 & 31 \\
\hline 5 & Ren [20] & 2017 & RS & 14 & $12 / 2$ & 40.4 & 3.3 & 8.5 & 15.3 & 17.5 \\
\hline 6 & van Niekerk [21] & 2017 & $\mathrm{RC}$ & 12 & - & 35.1 & - & 5.0 & - & - \\
\hline 7 & Hou [17] & 2015 & $\mathrm{RC}$ & 15 & $15 / 0$ & 31.28 & - & 4 & 10.29 & - \\
\hline 8 & Jing [19] & 2015 & RS & 58 & $38 / 20$ & 29.4 & 6.3 & 9.5 & 30.5 & 31.6 \\
\hline 9 & Leonard [18] & 2015 & RS & 7 & - & 29 & - & 7 & 3 & 28 \\
\hline 10 & Spiegl [16] & 2013 & PS & 25 & $22 / 3$ & 46 & - & 5.3 & 9.6 & 29.4 \\
\hline 11 & McHale [15] & 2004 & RS & 10 & $8 / 2$ & 31 & - & - & - & 36 \\
\hline
\end{tabular}

Abbreviations: RS: retrospective case series; RC: retrospective comparative study; PS: prospective case series.

3.3. Interventions and Outcomes. The intervention consisted of three main steps: radical surgical debridement, implantation of antibiotic-impregnated spacer, and Ilizarov methods. The Ilizarov methods included three techniques: bone transport, acute shortening and relengthening, and compression osteosynthesis. Except for one study [19] where the spacer was made of antibiotics and calcium sulfate, the spacers in the remaining studies were all made of antibiotics and bone cement. The shape of the spacer can be columnar or beadlike. Bone grafting as a routine treatment was recommended at the end of the bone transport in 2 included studies $[16,17]$. Suturing the induced membrane produced by the antibiotic spacer was reported in 3 included studies [18, 20, 21].

In the outcomes of included studies for infected nonunion of tibia, the average of the bone union rate was $94.67 \%$. The mean complications of every patient were 0.86 . The mean external fixation time was 13.18 months $[15,16$, $18-21]$. The mean external fixation index was 46.88 days $/ \mathrm{cm}$ $[16,18-21]$; further details are listed in Table 3. Details of major related complications are shown in Table 4.

3.4. Bone Results. The criteria recommended by Paley were adopted to evaluate clinical bone results in the studies [14, $17,19,20,22]$. Bone results were evaluated by 4 criteria: union, infection, deformity, and limb-length discrepancy.

(1) Excellent: fracture healing and three of the following indicators-no recurrent infection, local deformity less than $7^{\circ}$, and unequal length of limbs less than $2.5 \mathrm{~cm}$

(2) Good: fracture healing and any two of the 3 indicators above

(3) Fair: fracture healing and any one of the 3 indicators above

(4) Poor: fracture did not heal or fracture again or no match for any of the 3 indicators above [9]
5 studies with 107 patients reported the excellent rate in bone results. Since the heterogeneity test indicated no significant heterogeneity $\left(I^{2}=0.0 \%\right)$, a fixed-effect model was used. The meta-analysis showed that the excellent rate in bone results was $65 \%$ (95\% CI: [0.22, 0.97], Figure 2).

3.5. Infection Recurrence. 10 studies with 164 patients reported the infection recurrence in complications. Since the heterogeneity test indicated no significant heterogeneity $\left(I^{2}=0.0 \%\right)$, a fixed-effect model was used. The metaanalysis showed that the rate of the infection recurrence was $6.99 \%$ (95\% CI: [0.052, 0.325], Figure 3) after the antibiotic spacer combined with Ilizarov methods was applied to the infected nonunion of tibia.

3.6. Sensitivity Analysis. Although the heterogeneity test indicated that no significant heterogeneity was found $\left(I^{2}=0.0 \%\right)$, our research mainly includes retrospective case studies and cohort studies. To test the stability of the results of our study, we performed the sensitivity analysis. The results of the sensitivity analysis showed minor changes in ES and 95\% CI when one study was randomly removed from the metaanalysis, demonstrating that the results of our research are less sensitive and have good stability.

\section{Discussion}

As far as we acknowledge, this is the first systematic review about infected nonunion of tibia treated by an antibiotic spacer combined with Ilizarov methods. This systematic review included 11 studies, and we conducted a metaanalysis of the 11 studies to evaluate the actual efficacy of the antibiotic spacer combined with Ilizarov methods in the treatment of infected nonunion of tibia. The excellent rate in bone results was $65 \%$ (95\% CI: [0.22, 0.97]; $I^{2}=0.0 \%, P$ $=0.932)$. The reinfection rate after surgery was $6.99 \%(95 \%$ CI: $\left.[0.052,0.325], I^{2}=0.0 \%, P=1.000\right)$. And the data were 
TABLE 3: Interventions and outcomes of included studies.

\begin{tabular}{|c|c|c|c|c|c|c|c|}
\hline $\begin{array}{l}\text { Study } \\
\text { no. }\end{array}$ & The process of spacer & $\begin{array}{c}\text { Bone results (Paley) } \\
\text { (excellent/good/fair/poor) }\end{array}$ & $\begin{array}{l}\text { Functional results (Paley) } \\
\text { (excellent/good/fair/poor) }\end{array}$ & $\begin{array}{c}\text { EFT } \\
\text { (months) }\end{array}$ & $\begin{array}{c}\mathrm{EFI} \\
(\mathrm{cm} / \mathrm{d})\end{array}$ & $\begin{array}{l}\text { Complications } \\
\text { (per patient) }\end{array}$ & $\begin{array}{l}\text { Ingredients } \\
\text { of spacer }\end{array}$ \\
\hline 1 & $\begin{array}{l}\text { After RD, antibiotic } \\
\text { cement beads were } \\
\text { implanted. } 2 \text { weeks } \\
\text { later, spacer is } \\
\text { gradually removed } \\
\text { during bone transport. }\end{array}$ & - & $22 / 7 / 2 / 0$ & 1.7 & - & - & $\begin{array}{l}\text { Cement } \\
\text { mixed with } \\
\text { sensitive } \\
\text { antibiotics }\end{array}$ \\
\hline 2 & $\begin{array}{l}\text { After RD, antibiotic } \\
\text { cement was implanted. } \\
\text { After } 6 \text { weeks, the } \\
\text { spacer was removed } \\
\text { before bone transport. }\end{array}$ & - & - & 8.5 & - & $0.61(11 / 18)$ & $\begin{array}{c}20 \mathrm{~g} \text { cement } \\
\text { mixed with } \\
3-4 \mathrm{~g} \\
\text { vancomycin }\end{array}$ \\
\hline 3 & $\begin{array}{l}\text { After RD, antibiotic } \\
\text { spacers containing } \\
\text { calcium sulfate were } \\
\text { implanted and } \\
\text { eventually absorbed } \\
\text { naturally. }\end{array}$ & $11 / 1 / 0 / 0$ & - & 6 & - & $0.44(12 / 27)$ & $\begin{array}{l}\text { Solid } \\
\text { containing } \\
\text { calcium } \\
\text { sulfate } \\
\text { powder and } \\
\text { vancomycin }\end{array}$ \\
\hline 4 & $\begin{array}{l}\text { After RD, antibiotic } \\
\text { cement beads were } \\
\text { implanted. Spacer is } \\
\text { gradually removed } \\
\text { during bone transport. }\end{array}$ & $7 / 1 / 0 / 0$ & - & 4.4 & - & $2.25(18 / 8)$ & $\begin{array}{l}20 \text { g cement } \\
\text { mixed with } \\
0.25 \mathrm{~g} \\
\text { gentamicin } \\
\text { and } 3 \mathrm{~g} \\
\text { vancomycin }\end{array}$ \\
\hline 5 & $\begin{array}{l}\text { After RD, antibiotic } \\
\text { bone cement was } \\
\text { implanted. After } 4-7 \\
\text { weeks, the antibiotic } \\
\text { cement was removed } \\
\text { and induction } \\
\text { membrane was sutured. } \\
\text { The bone transport will } \\
\text { begin after } 7 \text { days. }\end{array}$ & - & - & 13.2 & 48.5 & $1.43(20 / 14)$ & $\begin{array}{l}10 \mathrm{~g} \text { cement } \\
\text { mixed with } \\
1 \mathrm{~g} \\
\text { vancomycin }\end{array}$ \\
\hline 6 & $\begin{array}{l}\text { After RD, antibiotic } \\
\text { bone cement was } \\
\text { implanted. After } 6 \\
\text { weeks, the antibiotic } \\
\text { cement was removed } \\
\text { and induced } \\
\text { membrane was } \\
\text { sutured. Besides, the } \\
\text { bone transport began. }\end{array}$ & - & - & 8.5 & 56.6 & $0.5(6 / 12)$ & $\begin{array}{l}\text { Antibiotic- } \\
\text { impregnated } \\
\text { cement }\end{array}$ \\
\hline 7 & $\begin{array}{l}\text { After RD and bone } \\
\text { grafting, the remaining } \\
\text { defects were filled with } \\
\text { bone cement } \\
\text { containing gentamicin. } \\
\text { After } 1 \text { week, the spacer } \\
\text { was removed before } \\
\text { bone transport. }\end{array}$ & $6 / 8 / 1 / 0$ & - & 7.5 & - & - & $\begin{array}{l}\text { Cement } \\
\text { mixed with } \\
\text { gentamicin }\end{array}$ \\
\hline 8 & $\begin{array}{l}\text { After RD, antibiotic } \\
\text { bone cement was } \\
\text { implanted. After 7-10 } \\
\text { days, spacer was } \\
\text { gradually removed } \\
\text { during bone transport. }\end{array}$ & $30 / 23 / 5 / 0$ & $28 / 18 / 12 / 0$ & 10.6 & 36 & $0.67(39 / 58)$ & $\begin{array}{l}10 \mathrm{~g} \text { cement } \\
\text { mixed with } \\
1.2 \mathrm{~g} \\
\text { tobramycin } \\
\text { and } 0.5 \mathrm{~g} \\
\text { vancomycin }\end{array}$ \\
\hline 9 & $\begin{array}{l}\text { After RD, antibiotic } \\
\text { bone cement was }\end{array}$ & - & - & 18 & 81 & $1.43(10 / 7)$ & $\begin{array}{l}40 \mathrm{~g} \text { cement } \\
\text { mixed with }\end{array}$ \\
\hline
\end{tabular}


TABLE 3: Continued.

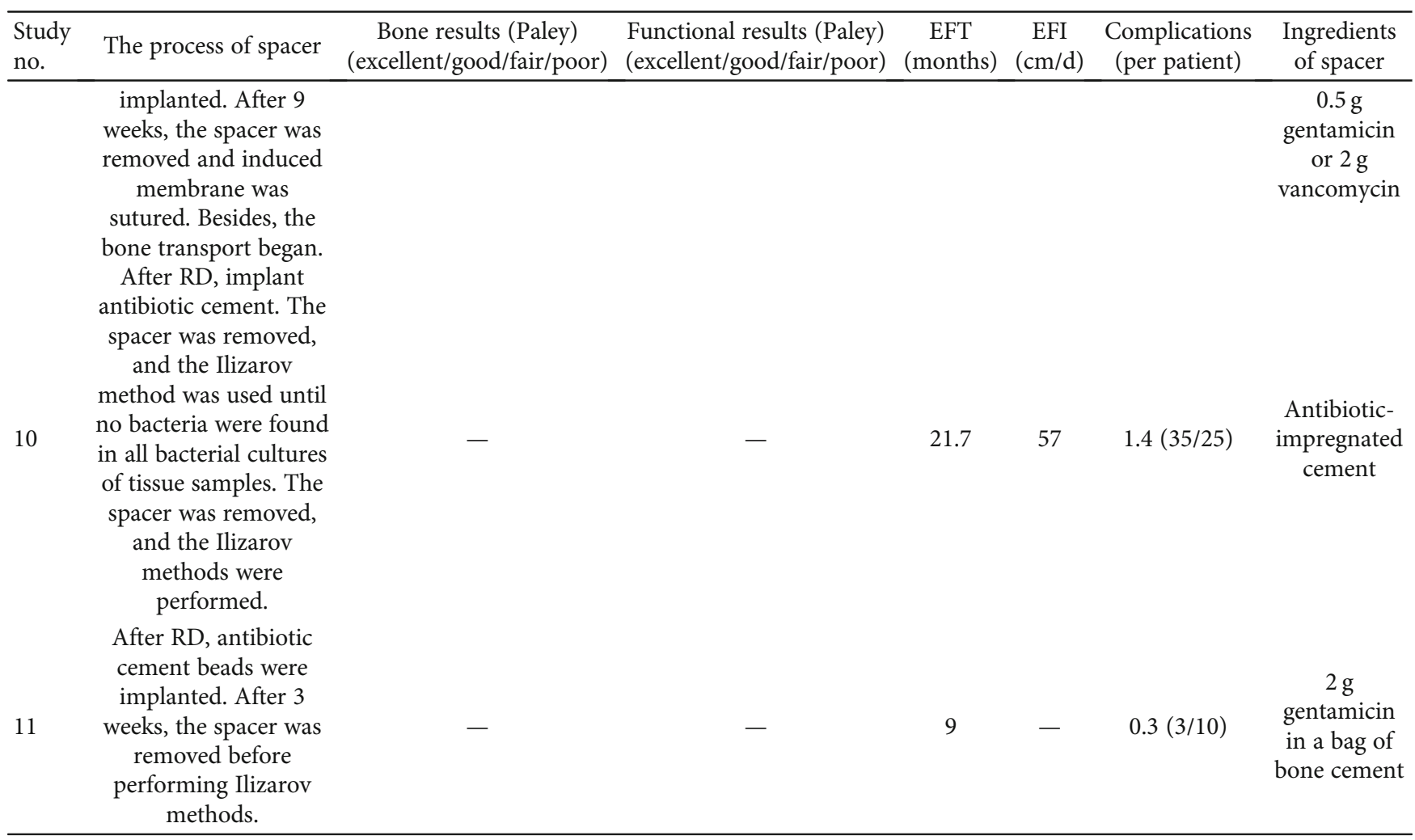

Abbreviations: RD: radical debridement; EFT: external fixation index; EFI: external fixation index.

TABLE 4: List of related complications.

\begin{tabular}{lc}
\hline Complications & Number of patients \\
\hline Pin tract infection or pin loosening & 53 \\
Axial deviation & 21 \\
Delayed union & 6 \\
Bone grafting & 4 \\
Joint stiffness & 10 \\
Malunion & 12 \\
Amputation & 2 \\
Refracture & 4 \\
Muscle contractures & 4 \\
\hline
\end{tabular}

not statistically heterogeneous. Therefore, our results showed that the patients with infected nonunion of tibia treated by antibiotic spacer combined with Ilizarov methods had a high rate of excellent bone results and a low rate of infectious recurrence.

According to a tibial anatomical study [25], besides less local soft tissue cover, the lower $2 / 3$ of the tibial luminal diaphysis has no vascular foramen, and only a small hole exists in the posterior side of the junction of the upper $1 / 3$ of the tibial luminal diaphysis. If a fracture occurs at the junction of the middle and lower $1 / 3$ of the tibia, it can damage the nutrient artery, resulting in reduced blood supply to the lower $1 / 3$ of the tibia. This predisposes the breeding of a large number of bacteria that is difficult to be cleared by the body, which can even form bacterial emboli leading to vascular blockage at the fracture end, tibial ischemia and necrosis, and local infection and purulence, evolving into chronic osteomyelitis eventually. Although infected nonunion of the tibia needs radical debridement to remove infected and necrotic bone, bacteria may still hide in the bone and soft tissue lacunae and cause repeated infection during the distraction process $[9$, 26]. Therefore, control of bacterial infection is also an important part in the treatment of infected nonunion of tibia. Currently, the main method of infection control was to select sensitive antibiotics according to the results of drug sensitivity and to take systemic administration [27]. However, the dosage of this method was large, and the adverse drug reactions are obvious. Furthermore, it is easy to cause drug resistance. More importantly, tibias with chronic osteomyelitis have poor local blood supply. It is difficult for systemic antibiotics to reach an effective concentration at the lesion site, so the purpose of infection control cannot be achieved [2].

After the local application of an antibiotic spacer, the local concentration of antibiotics was nearly 200 times higher than that of systemic administration. It is enough to kill drug-resistant bacteria. Moreover, bone cement can provide local support and facilitate early functional exercise [28], although there is no standard for the use of antibiotics in bone cement, because excessive addition will reduce the mechanical strength. But a study found that adding 8 grams of antibiotics to 40 grams of bone cement is still safe [29]. 


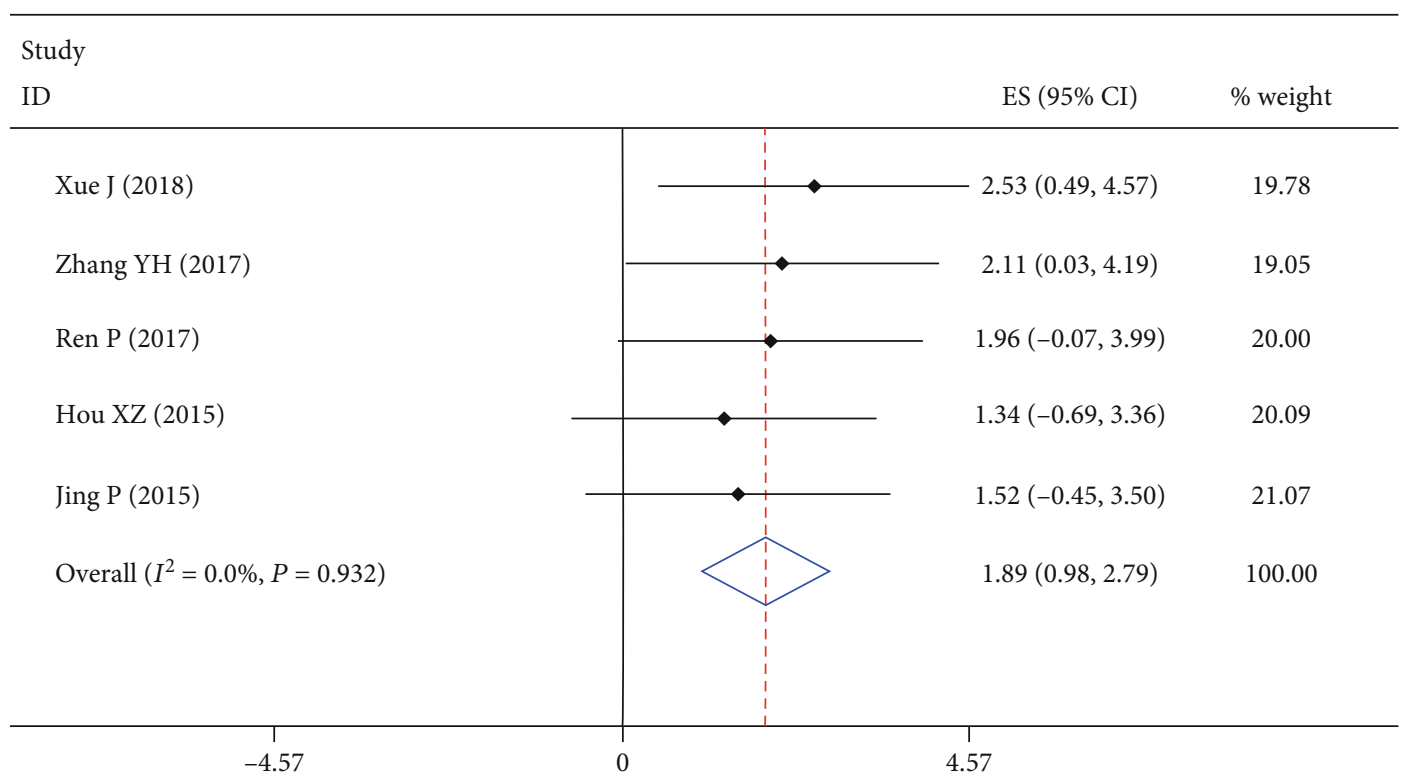

Figure 2: Forest plot showing excellent rate of bone results. According to the formula $\left(P=(\sin (x / 2))^{2}\right)$, the final rate was equal to 0.65 ; $95 \%$ CI ranged from 0.22 to 0.97 .

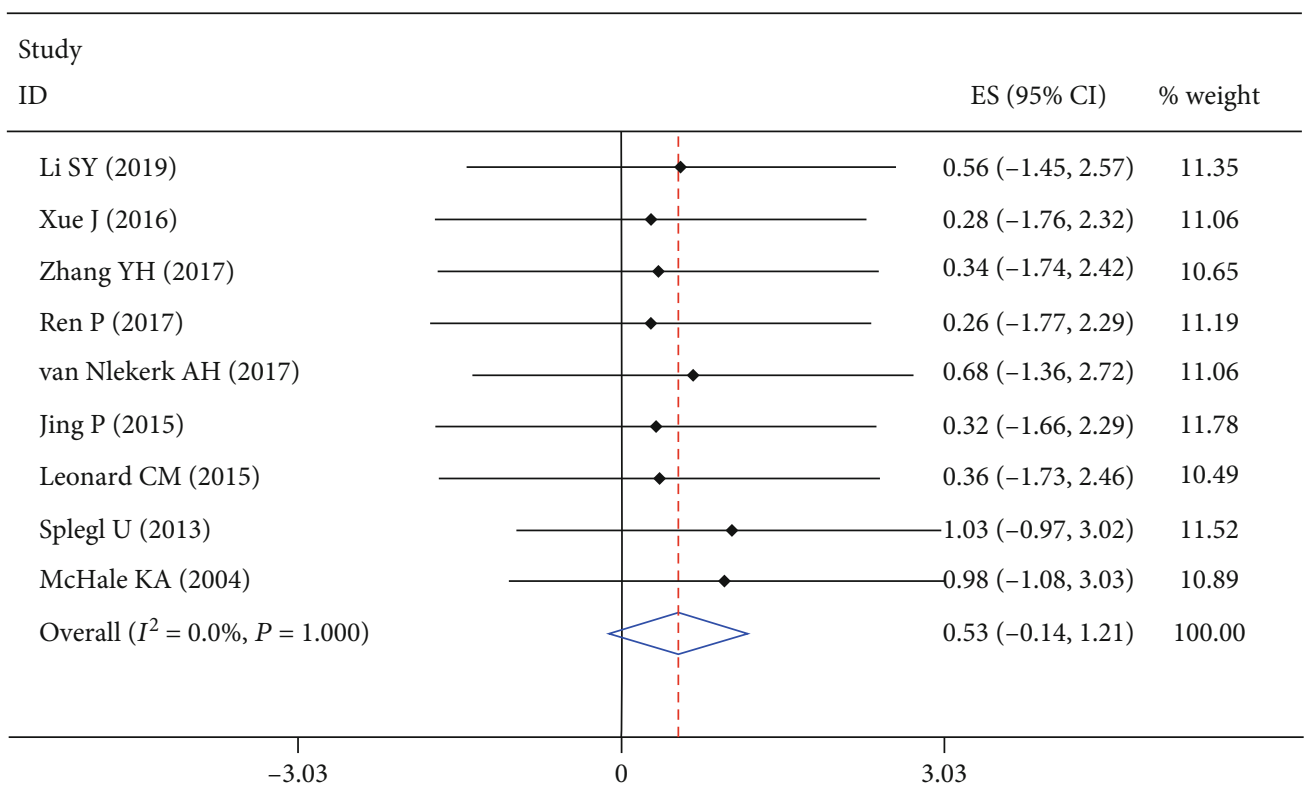

FIGURE 3: Forest plot showing rate of infection recurrence. According to the formula $\left(P=(\sin (x / 2))^{2}\right)$, the final rate was equal to $0.0699,95 \%$ CI ranged from 0.0518 to 0.325 .

Radical debridement and the antibiotic spacer can effectively eliminate the infection, but the bacteria residue and subsequent bone nonunion are other major problems for orthopedic surgeons [30]. At present, there are many reports recording the treatment of tibial defects with Ilizarov methods. Ilizarov methods based on the biological principles of distraction osteogenesis, solving the problems of bone defects and tissue loss in patients [31], have gradually become the main method for the treatment of infected nonunion of tibia.
The popularity of the Ilizarov technique is mainly due to the improvement of local blood supply, which can not only promote fracture healing but also enhance the ability to control infection. Meanwhile, for patients with a local defect of soft tissue in the injured area, bone transport can promote soft tissue to repair, which is also better than the Masquelet technology in this respect [32], since the bone is distracted to an appropriate length every day, the surrounding soft tissue regenerates along with the pulling force during bone transport, 
and the stimulation during bone transport for blood vessel and peripheral nerve around the defective area is also a contributing factor to the repair of soft tissue.

Therefore, the systematic review was conducted to estimate whether combined antibiotic cement spacer with Ilizarov methods in the treatment of infected nonunion of the tibia is an ideal approach. According to our meta-analysis, the rate of infection recurrence is lower than the rate in the study by Yin et al. using other treatments [11]. Besides, the rate of infection recurrence is also lower than $9.3 \%$ in the meta-analysis of the Masquelet technique by Morelli and colleagues [33].

Considering the external fixation index in our series (mean 46.88 days $/ \mathrm{cm}$ ), as well as the 49.2 days $/ \mathrm{cm}$ reported in the meta-analysis of Ilizarov methods by Yin et al. [11], it appears that the application of antibiotic spacers does not significantly increase the period of external fixation. Meanwhile, the excellent rate in bone results was 65\%. Compared with $61 \%$ in Yin et al. [11] only using Ilizarov methods, the treatment effect and satisfaction were improved.

Although this study comprehensively and systematically evaluated the efficacy of the antibiotic spacer combined with Ilizarov methods, there are still some limitations in our study. (1) The sample size in the studies involved was small, and most studies were retrospective studies. (2) The included researches lacked standardised and unified protocols for the process of treatment, especially the removal timing and removal method of the spacer. (3) Due to the lack of records of bone and functional results, many variables of included studies cannot be analyzed in combination, all of which may lead to bias in conclusions. Thus, further research based on prospective, largesize, and multicentre clinical study should be done.

Of course, some scholars believe that Ilizarov methods also have some shortcomings [34]: (1) The external fixator is clumsy, and wearing it for a long time will affect the patient's daily activities. (2) Due to the long time of treatment and slow speed of mineralization, a longer time is often needed to enhance the mechanical strength of the new bone segment. (3) The needle passage of the external fixator can provide an infection channel for bacteria. In order to avoid the occurrence of needle passage infection, frequent daily care for the needle passage is needed. (4) After bone transport, the docking site may not heal well, and it may even require surgery again. (5) In the process of bone transport, persistent pain can be caused by increased pressure in the soft tissue, continuous nerve stimulation and the inevitable occurrence of skin cutting. Therefore, it is necessary to comprehensively evaluate various factors, to select appropriate indications, and to flexibly apply different methods in order to complement each other's advantages and achieve the best effect.

\section{Conclusions}

Our research revealed that patients with infected nonunion of tibia treated by antibiotic spacer combined with the Ilizarov methods had a high rate of excellent bone results and low rate of infection recurrence. Therefore, combined antibiotic spacer with Ilizarov methods may be an applicable choice for repairing and reconstructing infected nonunion of tibia.

\section{Abbreviations}

95\% CI: $95 \%$ confidence interval

CNKI: China National Knowledge Infrastructure

EFI: External fixation index.

\section{Data Availability}

All data used to support the findings of this study are included within the article.

\section{Conflicts of Interest}

The authors declare that they have no conflicts of interest.

\section{Authors' Contributions}

Fubing Li and Liangjun Yin contributed equally to this work and are cocorresponding authors.

\section{Acknowledgments}

This study was funded by the Kuanren Talents Program of the Second Affiliated Hospital of Chongqing Medical University (KY2019L013), Chongqing Science and Technology Commission Social and People's Livelihood Project (cstc2017shmsA130049), and Yunnan Provincial Traumatology and Orthopedic Clinical Medicine Center Project (ZX20191001).

\section{References}

[1] R. Rohilla, J. Wadhwani, A. Devgan, R. Singh, and M. Khanna, "Prospective randomised comparison of ring versus rail fixator in infected gap nonunion of tibia treated with distraction osteogenesis," The bone \& joint journal, vol. 98-B, no. 10, pp. 1399-1405, 2016.

[2] N. S. Motsitsi, "Management of infected nonunion of long bones: the last decade (1996-2006)," Injury, vol. 39, no. 2, pp. 155-160, 2008.

[3] R. Rohilla, P. K. Sharma, J. Wadhwani et al., "Prospective randomized comparison of quality of regenerate in distraction osteogenesis of ring versus monolateral fixator in patients with infected nonunion of the tibia using digital radiographs and ct," The bone \& joint journal, vol. 101, pp. 1416-1422, 2019.

[4] G. Cierny 3rd and K. E. Zorn, "Segmental tibial defects. Comparing conventional and Ilizarov methodologies," Clinical orthopaedics and related research, vol. 301, pp. 118-123, 1994.

[5] E. E. Zaidenberg, E. Martinez, and C. R. Zaidenberg, "Vascularized distal radius bone graft for treatment of ulnar nonunion," The Journal of Hand Surgery, vol. 43, pp. 685.e1685.e5, 2018.

[6] T. F. Raven, A. Moghaddam, C. Ermisch et al., "Use of Masquelet technique in treatment of septic and atrophic fracture nonunion," Injury, vol. 50, Suppl 3, pp. 40-54, 2019.

[7] R. Morris, M. Hossain, A. Evans, and I. Pallister, "Induced membrane technique for treating tibial defects gives mixed results," The bone \& joint journal, vol. 99, pp. 680-685, 2017.

[8] D. Giotikas, N. Tarazi, L. Spalding, M. Nabergoj, and M. Krkovic, "Results of the induced membrane technique in the management of traumatic bone loss in the lower limb: a 
cohort study," Journal of Orthopaedic Trauma, vol. 33, no. 3, pp. 131-136, 2019.

[9] D. Paley and D. C. Maar, "Ilizarov bone transport treatment for tibial defects," Journal of Orthopaedic Trauma, vol. 14, no. 2, pp. 76-85, 2000.

[10] A. D. Kanellopoulos and P. N. Soucacos, "Management of nonunion with distraction osteogenesis," Injury, vol. 37, no. 1, pp. S51-S55, 2006.

[11] P. Yin, Q. Ji, T. Li et al., "A systematic review and metaanalysis of Ilizarov methods in the treatment of infected nonunion of tibia and femur," PLoS One, vol. 10, no. 11, article e0141973, 2015.

[12] Y. Liu, M. Yushan, Z. Liu, J. Liu, C. Ma, and A. Yusufu, "Complications of bone transport technique using the Ilizarov method in the lower extremity: a retrospective analysis of 282 consecutive cases over 10 years," BMC Musculoskeletal Disorders, vol. 21, no. 1, p. 354, 2020.

[13] G. Wen, R. Zhou, Y. Wang, S. Lu, Y. Chai, and H. Yang, "Management of post-traumatic long bone defects: a comparative study based on long-term results," Injury, vol. 50, no. 11, pp. 2070-2074, 2019.

[14] Y. Zhang, S. Qin, and D. Wang, "Bone transport for treatment of chronic tibia osteomyelitis: is antibiotics bone cement necessary," Orthopedic Journal of China, vol. 25, pp. 331-335, 2017.

[15] K. A. McHale and A. E. Ross, "Treatment of infected tibial nonunions with debridement, antibiotic beads, and the Ilizarov method," Military Medicine, vol. 169, no. 9, pp. 728734, 2004.

[16] U. Spiegl, R. Pätzold, J. Friederichs, S. Hungerer, M. Militz, and V. Bühren, "Clinical course, complication rate and outcome of segmental resection and distraction osteogenesis after chronic tibial osteitis," Injury, vol. 44, no. 8, pp. 1049-1056, 2013.

[17] X. Z. Hou, Q. Fu, S. J. Yan, and F. Li, "Effect of antibiotic cement combined with iizarov external fixator accordion technique in the treatment of tibial severe chronic osteomyelitis bone defects and Paley healing evaluation," China Pharmaceuticals, vol. 24, pp. 139-140, 2015.

[18] L. C. Marais and N. Ferreira, "Bone transport through an induced membrane in the management of tibial bone defects resulting from chronic osteomyelitis," Strategies in Trauma and Limb Reconstruction, vol. 10, no. 1, pp. 27-33, 2015.

[19] J. Peng, L. Min, Z. Xiang, F. Huang, C. Tu, and H. Zhang, "Ilizarov bone transport combined with antibiotic cement spacer for infected tibial nonunion," International Journal of Clinical and Experimental Medicine, vol. 8, no. 6, pp. 10058-10065, 2015.

[20] P. Ren, A. Abulaiti, M. Xiayimaierdan et al., "Treatment of post-traumatic tibial osteomyelitis by two-stage bone transport combined with induced membrane technique," Chinese Journal of Orthopaedic Trauma, vol. 19, pp. 880-885, 2017.

[21] A. H. van Niekerk, F. F. Birkholtz, P. de Lange, K. Tetsworth, and E. Hohmann, "Circular external fixation and cemented PMMA spacers for the treatment of complex tibial fractures and infected nonunions with segmental bone loss," Journal of Orthopaedic Surgery (Hong Kong), vol. 25, no. 2, pp. 230949901771624-230949901771628, 2017.

[22] J. Xue, M. Zhu, W. Y. Xie, and K. B. Huang, "Clinical analysis of the Ilizarov technique combined with Masquelet technique in the treatment of tibial bone infection (in 12 cases)," Journal of Logistics University of PAP, vol. 27, pp. 147-149, 2018.
[23] S. Y. Li, Q. S. Zhou, Y. Li, and C. Chen, "Effect analysis of the treatment of segmental bone defect with tibial osteomyelitis treated by induced membrane combined with bone transport technique," Chinese Journal of Orthopaedic Trauma, vol. 27, pp. 33-36, 2019.

[24] H. Wang, C. S. Zhou, and K. Zhang, "Efficacy of bone cement combined with Ilizarov technique on limb function and wound bacterial content in patients with tibia chronic osteomyelitis," Hebei Medicine, vol. 25, pp. 567-572, 2019.

[25] H. Almansour, E. Armoutsis, M. K. Reumann, K. Nikolaou, and F. Springer, "The anatomy of the tibial nutrient artery canal-an investigation of 106 patients using multi-detector computed tomography," Journal of Clinical Medicine, vol. 9, 2020.

[26] H. Bezstarosti, W. J. Metsemakers, E. M. M. van Lieshout et al., "Management of critical-sized bone defects in the treatment of fracture-related infection: a systematic review and pooled analysis," Archives of Orthopaedic and Trauma Surgery, 2020.

[27] N. Hassani Besheli, F. Mottaghitalab, M. Eslami et al., "Sustainable release of vancomycin from silk fibroin nanoparticles for treating severe bone infection in rat tibia osteomyelitis model," ACS Applied Materials \& Interfaces, vol. 9, no. 6, pp. 5128-5138, 2017.

[28] B. D. Springer, G. C. Lee, D. Osmon, G. J. Haidukewych, A. D. Hanssen, and D. J. Jacofsky, "Systemic safety of high-dose antibiotic-loaded cement spacers after resection of an infected total knee arthroplasty," Clinical Orthopaedics and Related Research, vol. 427, pp. 47-51, 2004.

[29] X. Liu, G. Ding, D. Zhou, and L. Xiang, “Antibiotic-loaded bone cement spacer usage combined with membrane induction in infected gap non-unions: a case series," Pakistan journal of medical sciences, vol. 34, pp. 1088-1093, 2018.

[30] S. A. Abdou, J. T. Stranix, D. A. Daar et al., "Free tissue transfer with distraction osteogenesis and Masquelet technique is effective for limb salvage in patients with Gustilo type IIIB open fractures," Plastic and Reconstructive Surgery, vol. 145, no. 4, pp. 1071-1076, 2020.

[31] M. S. Khan, H. Rashid, M. Umer, I. Qadir, K. Hafeez, and A. Iqbal, "Salvage of infected non-union of the tibia with an Ilizarov ring fixator," Journal of Orthopaedic Surgery (Hong Kong), vol. 23, no. 1, pp. 52-55, 2015.

[32] K. Aktuglu, K. Erol, and A. Vahabi, "Ilizarov bone transport and treatment of critical-sized tibial bone defects: a narrative review," Journal of Orthopaedics and Traumatology, vol. 20, no. 1, p. 22, 2019.

[33] I. Morelli, L. Drago, D. A. George, E. Gallazzi, S. Scarponi, and C. L. Romanò, "Masquelet technique: myth or reality? A systematic review and meta-analysis," Injury, vol. 47, Suppl 6, pp. S68-s76, 2016.

[34] D. Gulabi, M. Erdem, G. S. Cecen, C. C. Avci, N. Saglam, and F. Saglam, "Ilizarov fixator combined with an intramedullary nail for tibial nonunions with bone loss: is it effective?," Clinical Orthopaedics and Related Research, vol. 472, no. 12, pp. 3892-3901, 2014. 